\title{
Theory into Practice: Applying David Jonassen's Work in Instructional Design to Instruction Programs in Academic Libraries
}

\section{Alexius Smith Macklin}

The Association of College and Research Libraries (ACRL) recently updated the guidelines for instruction programs in academic libraries. This revised document includes the use of active learning techniques and instructional design tools for program development. Research in education currently contains a wealth of theories and strategies in these areas that are useful to instruction librarians. In particular, the work of David $\mathrm{H}$. Jonassen is rich with guidance on designing active learning environments for problem solving and information retrieval. This article outlines how Jonassen's research can provide a working context for using the ACRL guidelines to create successful instruction programs.

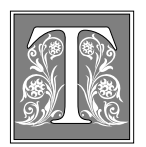

he guidelines for instruction programs are very clear with regard to academic libraries establishing a culture of instruction based on the specific needs of the learning communities they serve. ${ }^{1}$ Rather than prescribing a formula for success, this document broadly outlines some basic strategies for designing programs that recognize diversity among disciplines and institutions. In addition, the programs that develop out of these guidelines must address the various learning styles, life experiences, skill levels, and individual needs of learners within the framework of their community. This type of planning and design is a lot to ask of librarians, who, until recently, did not consider themselves teachers, much less creators and implementers of instruction programs. Now, with more institutions recognizing the importance of information skill building, librarians must be strategic partners supporting, developing, and carrying out educational goals both inside and outside the library.

So how do you determine the evolving information literacy needs of your learning community? And when you know those needs, how do you align them with the Information Literacy Competency Standards for Higher Education? ${ }^{2}$ Finally, how do you integrate a comprehensive program of information literacy instruction into the curriculum without disrupting the flow of learning? Many instruction librarians are struggling with these questions as they work to establish

Alexius Smith Macklin is User Instruction Librarian and Assistant Professor at Purdue University; email: alexius@purdue.edu. 
meaningful programs and partnerships across campus. There is no one right way to answer these pressing questions, nor one right formula for creating good instruction programs. However, there are some characteristics of best practice, and significant research is being done in the areas of instructional design and cognitive psychology that may help direct a course of action when planning a program of instruction. ${ }^{3}$

David Jonassen, Distinguished Professor of Learning Technologies at the University of Missouri, is an expert in instructional design and the implementation of innovative learning theories. His work on creating cognitive learning environments (CLEs), along with the ACRL guidelines on best practices for instruction programs, provides a useful framework for librarians who are responsible for curriculum development and instructional design projects. The key elements for this framework are listed in the order in which they should be considered when outlining an exemplary instruction program. ${ }^{4}$

1. A plan to establish and develop your instruction program: How will you be a strategic partner with subject area faculty in meeting instructional goals and objectives?

2. A method for advancing an existing program: How will you (and your faculty partner) develop meaningful learning experiences for the students and relate the instruction to work that is important to them (i.e., a research paper, project, or assignment)?

3. A strategy for revitalizing and sustaining partnerships: How will you use resources and successful experiences to maintain working relationships and to reach a broader population?

4. Assessment: How will you measure the overall impact of instruction and evaluate the individual learner's understanding?

\section{Establishing and Developing Instruction Programs}

Opening the doors to communication can seem daunting, if not impossible, for li- brarians who are not used to proactively approaching faculty on instruction matters. To initiate these conversations, librarians may want to ask faculty a simple question such as "Are your students finding and using the best information sources for assignments in your class?" The answer will likely be no. As faculty members begin to elaborate on specific problems, librarians can start identifying where and how to best integrate instruction.

For example, one frustration frequently mentioned is use of the Web as the only place to find information. In an effort to combat the compulsion to access and use an influx of inappropriate Webaccessible resources, well-intentioned professors are enforcing rules such as "No Internet materials may be included in this paper." Librarians know that an abundance of information is available in electronic full-text journals that students are not using because of these imposed limitations. Rather than relying on the standard fifty-minute lecture about various databases the library offers, using Jonassen's approach, the instruction librarian may consider asking whether he or she might collaborate with the professor to incorporate information resources-and strategies for using themdirectly into the course content. This approach is frequently more appealing to faculty who do not want to give up valuable classroom time for additional library instruction.

Integrated instruction requires faculty to work with librarians (often throughout the entire semester) in designing and creating learning tools and activities that explore learners' understandings and ways of thinking about using information to complete assignments and projects. Jonassen and Henning describe this as a constructivist approach to learning and argue that it is essential to understand and assess a learner's mental models as part of the instructional design process. ${ }^{5}$ These models are the internal conceptual and operational representations that humans develop while interacting with complex 
systems. For example, as learners engage in problem-solving activities in a constructivist learning environment, they reveal their thinking (the knowledge in their heads) through language, written texts, or symbols.

\section{Advancing an Existing Program}

Existing programs also can benefit from Jonassen's instructional design approach with the integration of activities that elicit problem-solving behaviors or thinking. Active learning techniques, which are very popular, do not always reveal how a student is thinking about finding and using information. A problem-solving approach may be the best method of instruction for knowledge construction (of the content and the appropriate information sources) and measuring the learner's thought process. For example, a forestry professor wanted to incorporate information skills into her upper-level policy course. She described some current issues in forestry that the instruction librarians adapted for use in team-based problemsolving activities. To make it even more interesting for the students, the solutions were shared with forest rangers working with the Department of Natural Resources, who provided feedback and guidance to the groups. In this environment, the learning goals developed as the students constructed their own understandings of the problem scenarios and used the information they found (on the Web and elsewhere) to create workable solutions.

Ikseon Choi and Jonassen question the need to produce detailed goals and objectives to measure learning outcomes as part of the instructional design process. ${ }^{6}$ They believe that contemporary perspectives on learning, such as constructivism, generate more effective goal structures that are student driven rather than teacher driven. This approach to learning puts students in situations where they must test and refine their thinking. This is best done through activities that are meaningful to the learner. For example, a professor in landscape architecture wanted her students to participate in the kinds of problem-solving experiences landscape designers face every day. She created a learning environment in which the students looked at the same problem from different perspectives. To facilitate this, she and a collaborating instruction librarian wrote a request for proposal (RFP) to revitalize a section of the city that was very run down. The students were assigned to groups and told to think about who the stakeholders were in the RFP. They then were asked to pick a point of view to consider when creating the design plan. One group elected to look at the problem from the perspective of the neighborhood association; another group took the position of the community development corporation; and a third group decided to see how Habitat for Humanity fit into the proposal. Each group was collecting inventory and data on the same location, but for different purposes and, obviously, different outcomes.

This situation allowed the students to establish their own plan for learning about the design process through written agreements (contracts) they made with the other group members. During weekly meetings with the instruction librarian, the groups determined their information needs, identified data to collect and developed a method for gathering them, analyzed what they found, and produced a design plan for a panel of experts to review. Immediate ownership of the problem took place as the groups co-created their own learning objectives with the professor. Rather than having six groups presenting six different landscape designs, there were six groups presenting six different research projects to support their landscape design. They learned from the process of working through the RFP; they learned from other members of the group; they learned from their peers; they learned from the professor and the librarian involved in the course; and they learned from the panel of experts selected to evaluate their presentations.

Jonassen has presented a cohesive model for designing constructivist learn- 
ing environments (CLEs) that engage the learner in knowledge construction through problem-solving activities. ${ }^{7}$ In this model, the use of objectivist and constructivist methods as complementary design tools is advocated because CLEs are not appropriate for every learning situation. According to Jonassen, the fundamental difference between the objectivist and constructivist methods is how the problem-solving activity drives the instruction. In the objectivist design, students solve a problem as an application of learning. In the CLE design, students must build on their existing knowledge and learn the domain content in order to solve the problem. CLEs include three integrated components:

- the problem context;

- the problem [re]presentation or simulation;

- the problem manipulation space.

The problem context describes the factors that surround the problem statement. For example, in the forestry course, the professor and two instruction librarians developed five problems dealing with the Clean Water Act. ${ }^{8}$ To begin the information retrieval process, the problems needed to put forward enough information to identify whether there was a point source, a nonpoint source, or a wetland situation. This kind of information is typically background or factual in nature and must be presented in a way that immediately engages the learner. Often problem simulation occurs as a narrative or story, as in the following example:

Phil T. Rich, Ph.D., is an eccentric millionaire who has acquired several hundred acres of land a few miles from the Wabash River southwest of Lafayette, Indiana. Dr. Rich already has built a massive mansion on the property and commissioned a small amount of landscaping directly adjoining the building. $\mathrm{He}$ now wishes to expand the landscaping to the surrounding twenty acres to achieve his vision of recreating an English Midlands Regency-era manor grounds. To this purpose, he hired the Anachronistic Landscaping Corporation and the company approached your team for advice. Four of these twenty acres are wetlands. In the current plans, a large pond (two acres of surface area) will be created by dredging some of the wetlands. A small stream originates in this section of the property and meanders through the rest of the property before feeding into the Wabash where the threatened species of fish Watercus spawns.

Your job is to guide the Anachronistic Landscaping Corporation and Dr. Rich through the process of getting the landscaping approved and the job completed. You need to know how to progress with the project and provide a plan of action to ensure that all regulations are followed.

In this course, each of the narratives described a controversial issue or some dilemma. Second, the problems were authentic and designed to give students skills they would actually use in real life. Finally, the problems were complex enough to require the entire group of learners to work together on solutions. More important, the motivation to find the best solution was built into the problem manipulation space, where students tested and revised their answers based on the feedback they received. Each group was required to present its solution(s) to its peer groups and to professionals working in the field of natural resources. These presentations included graphs, charts, and maps of their data analysis that could be used to defend their answers to a panel of experts. As the project unfolded, the use of instructional design tools was enormously helpful for keeping the learners on task and on schedule for completion.

There are many types of problem situations. Jonassen takes on the challenge of defining various problems for instruction purposes, their structuredness, their representations, and their complexities. He 
differentiates between well-structured problems (story or word problems in mathematics textbooks) and ill-structured problems (situations in everyday life), and explains that when the nature of problems differs, so, too, must the instructional design used to support the development of problem-solving skills. ${ }^{9}$ The point is to find a problem that is of interest and engages learners to think. After selecting a problem to investigate, it is important to determine whether a wellstructured problem statement is appropriate or whether an ill-structured one is more suited to the learning goals. In the case of the landscape architecture course, the professor wanted her students to have a real-world problem-solving experience. She chose to write an ill-structured problem with her librarian colleagues and required the students to establish their own learning outcomes. Some structure was necessary because the students needed to stay within the parameters of the RFP, but it was not a step-by-step, well-defined situation. This example fits the four characteristics that Jonassen describes for the ill-structured problem: ${ }^{10}$

- elements that are unknown or not known with any degree of confidence;

- multiple solutions, solution paths, or no solution at all;

- multiple criteria for evaluating solutions;

- assumptions made by the learner about the given problem.

When the desired learning outcomes require the student to apply clearly defined rules, using a well-structured problem is the best method. An example of this is a situation where the students must demonstrate their understanding of Boolean logic in conducting a search strategy. To obtain the most relevant results, the students would need to know that the use of the operator AND is inclusive of two or more keywords. An example from the forestry class is (wetlands AND pollution) and means that only information containing both terms will be searched. Well-defined problems also have the following characteristics: ${ }^{11}$
- All of the elements of the problem are presented to the learner.

- Alimited number of rules and principles are organized in predictive and prescriptive ways (AND will always mean the inclusion of two or more keywords).

- Solutions are knowable and comprehensible.

The forestry professor used a wellstructured approach to introduce her students to various information sources prior to working on the more complex problem-solving activities. She collaborated with instruction librarians who were able to help her identify useful resources for her course, including full-text databases, reference books, government documents, and a variety of relevant Web sites. The librarians arranged these information sources for ease of access and use. In addition to the selection of materials, the librarians were actively involved in the evaluation of the students' work and maintained statistics on which resources were used to complete assignments. To provide a comprehensive resource list, the librarians suggested that the students submit additional materials they found useful, which were placed in a shared file. This well-structured activity was an excellent way of preparing them to take on the challenges of the ill-structured problem-solving activities that followed. The students now were familiar with a variety of resources and appropriately accessed them to find, select, evaluate, and use the information for the problem-solving activities.

\section{Revitalize and Sustain Partnerships}

As Howard Gardner said, "You cannot know a theory until you put it into practice." ${ }^{12}$ Using Jonassen's theory on the development of CLEs helps to revitalize existing instruction programs and sustain successful partnerships. First, when a program needs fresh ideas, it is important to consider the tools available-for example, new information technologies acquired by the library, a recently purchased reference collection that needs a good introduction, 
TABLE 1

Student Self-assessment of The Learning Process in the Forestry Course

\begin{tabular}{lcc} 
As a result of this course: & \# Students Surveyed & \% Agreed \\
\hline My problem solving skills improved & 57 & $68 \%$ \\
$\begin{array}{l}\text { I learned new information and problem-solving } \\
\quad \text { skills that I can apply to other experiences }\end{array}$ & 57 & $84 \%$ \\
I am better able to find and select information & 57 & $77 \%$ \\
I can evaluate the information I find more effectively & 57 & $63 \%$
\end{tabular}

or interesting multimedia materials that would enhance course content. Next, it is important to think about what services to provide. What databases will be most useful to the students? Are there any Web sites to bookmark? Are there any books or monographs that can be placed on reserve that are relevant to the content of the problem? Is software available for data collection and analysis? Where will the students store their data? In the forestry and landscape architecture courses, the librarians revitalized the instruction program and created sustainable partnerships with the subject area faculty members by integrating digital libraries of resources and instructional tools that the students could use for solving their problems (now and in future semesters). These were developed in the course management software WebCT to password-protect materials for both copyright issues and student privacy. In addition, WebCT allowed students to keep their work in an electronic portfolio so that the individual group members, the professors, and the librarians could access information, monitor progress, and provide feedback. This interaction fully engaged participants and provided librarians with a unique way to evaluate their overall impact on the course.

Building sustainable partnerships with faculty is a commitment of time and resources. In the case of both the forestry and landscape design courses, librarians worked with the faculty members for approximately four weeks prior to the start of the semester outlining instruction plans, learning course content, identifying information resources, designing digital libraries to house materials, and creat- ing rubrics for assessing learning outcomes. Working with diverse groups of librarians made the job easier, and everyone's talents were engaged to make the collaborations highly successful. For example:

- Librarians who specialized in the subject matter of the life sciences identified databases and information sources most relevant to course content.

- Librarians with expertise in Web design were responsible for organizing the information and creating digital library structures.

- Librarians with experience in instructional design created teaching materials, including problem scenarios and assessment tools.

After the courses were established, the librarians continued to participate in both classes through individual interactions with student work groups, online discussions, assessment of students' assignments, and instruction on using various databases either in a lecture demonstration session or through online tutorials developed for the courses. The results were worth the investment of time and talent. Overall, the course evaluations were very positive and the students reported a favorable experience. Table 1 charts student self-assessment of the learning process in the forestry course.

\section{Assessment}

Jonassen claims that problem-solving skills are the most difficult to teach because we do not understand these activities well enough to support them. He further states that every problem has two critical attributes. The first is an unknown 
entity in a given situation. The second is some social, cultural, or intellectual value in the unknown. ${ }^{13}$ If there is no desire for an answer, there is no problem. When the learner determines that a problem is worth solving, he or she can begin to imagine a solution. For every problem scenario, there is an individual level of interpretation that takes into consideration a learner's own experiences, domain knowledge, bias, and so on. These all become part of the mental model. To evaluate the effectiveness of the model, learners must be trained to think about how they are thinking. This is called metacognition. The problems described in the forestry and landscape architecture courses are examples of how CLEs are used to document, refine, and evaluate the learner's reasoning processes and critical thinking. Librarians are well equipped to work in these learning environments because they engage in knowledge-building activities daily through interactions at the reference desk, collection development activities, and the management of complex information systems. The collaborative development of CLEs, where the students are guided through problemsolving experiences via integrated library instruction, is invaluable to high academic achievement and curriculum development. Librarian partners bring the expertise of knowing — almost innately — how to assess whether a learner is identifying information needs appropriately, finding and evaluating resources efficiently, and using those resources effectively to solve problems for course assignments and realworld experiences.

\section{Notes}

1. The final document of the ACRL Guidelines for Instruction Programs in Academic Libraries is available online from http://www.ala.org/Content/NavigationMenu/ACRL/ Standards_and_Guidelines/Guidelines_for_Instruction_Programs_in_Academic_Libraries1.htm.

2. The Information Literacy Competency Standards for Higher Education are available online from http:/ / www.ala.org/Content/NavigationMenu/ACRL/Standards_and_Guidelines / Information_Literacy_Competency_Standards_for_Higher_Education.htm.

3. David H. Jonassen, Rebecca Jo Hennon, Anita Ondrusek, Marina Samouilova, Karen L. Spaulding, Hsiu-Ping Yueh, Tiancheng Li, Vida Nouri, Mark. Di Rocco, and David Birdwell, "Certainty, Determinism, and Predictability in Theories of Instruction Design: Lessons from Science," Educational Technology 37 (Jan.-Feb. 1997): 27-34.

4. "Characteristics of Programs of Information Literacy That Illustrate Best Practices: A Guideline." Availableonlinefrom:http://www.ala.org/Content/NavigationMenu/ACRL/Standards_and_Guidelines/ Characteristics_of_Programs_of_Information_Literacy_that_lllustrate_Best_Practices.htm.

5. David. H. Jonassen and Philip Henning, "Mental Models: Knowledge in the Head and Knowledge in the World," Educational Technology 39 (May-June1999): 37-42.

6. Ikseon Choi and David H. Jonassen, "Learning Objectives from the Perspective of the Experienced Cognition Framework," Educational Technology 40 (Nov.-Dec. 2000): 36-40.

7. Jonassen, "Designing Constructivist Learning Environments," in Instructional-Design Theories and Models: A New Paradigm of Instructional Theory, Volume II, ed. Charles M. Reigeluth (Mahwah, N.J.: Erlbaum, 1999).

8. These problems were written by Shorna Broussard (subject matter expert), Brook Freeman, and Alexius Smith Macklin (instruction librarians). They are available online from http:/ / www.lib.purdue.edu/Leader_Forestry.

9. Jonassen, "Toward a Design Theory of Problem Solving," Educational Technology Research and Development 48 (2000): 63-85.

10. Ibid.

11. Ibid.

12. Howard Gardner, "Multiple Approaches to Understanding," in Instructional-Design Theories and Models: A New Paradigm of Instructional Theory, Volume II, ed. Charles M. Reigeluth (Mahwah, N.J.: Erlbaum, 1999).

13. Jonassen, "Can You Train Employees to Solve Problems?" Performance Improvement 40 (2001): 16-22. 